\title{
PERCEPÇÕES DE GESTANTES ACERCA DA PARTICIPAÇÃO DO COMPANHEIRO NA GESTAÇÃO
}

\author{
PERCEPTIONS OF PREGNANT WOMEN ABOUT THE \\ PARTICIPATION OF THE PARTNER IN PREGNANCY
}

\begin{abstract}
Naiashy Vanuzzi Martello', Laís Antunes Wilhelm², Luiza Cremonese', Camila Neumaier Alves ${ }^{3}$, Lisie Alende Prates ${ }^{4}$, Lúcia Beatriz Ressel ${ }^{5}$
\end{abstract}

\section{RESUMO}

O objetivo deste estudo é compreender como as mulheres percebem a participação do homem no processo gravídico. Pesquisa de campo, do tipo descritiva, com abordagem qualitativa, desenvolvida com treze gestantes de um município do interior do Rio Grande do Sul, Brasil. Os dados foram coletados por meio da entrevista semiestruturada. Para análise de dados, adotou-se a análise de conteúdo temática da proposta operativa. As percepções das gestantes abrangeram três perspectivas: o companheiro participa do processo gestacional, o companheiro mantém-se distante e o companheiro não inclui a mulher nos preparativos para a chegada do bebê. Reforça-se a importância da participação conjunta do casal, fundamental para a família se estabelecer como um grupo em formação.

Descritores: Saúde da Mulher; Gravidez; Paternidade; Cuidado Pré-Natal.

\begin{abstract}
The objective of this study is to understand how women perceive participation in gravid process. Field research, of the descriptive type, with qualitative approach, developed with thirteen pregnant women of a municipality within the Rio Grande do Sul, Brazil. Data were collected through the semi-structured interview. For analysis of data, the analysis of the thematic content of the operational proposal was adopted. The perceptions of the pregnant women covered three perspectives: the partner participates in the gestational process, the companion remains distant and the companion does not include the woman in the preparations for the arrival of the baby. It reinforces the importance of the joint participation of the couple, fundamental for the family to establish itself as a group in formation.
\end{abstract}

Descriptors: Women's Health; Pregnancy; Paternity; Prenatal Care.
${ }^{1}$ Enfermeira graduada pela Universidade Universidade Federal de Santa Maria (UFSM), Santa Maria, RS, Brasil.

${ }^{2}$ Enfermeira. Doutoranda em Enfermagem pelo Programa de Pós-Graduação em Enfermagem da UFSM. Santa Maria, RS, Brasil.

${ }^{3}$ Enfermeira. Doutoranda em Enfermagem pelo Programa de Pós-Graduação em Enfermagem da Universidade Federal de Pelotas (UFPel). Docente do Centro Universitário Ritter dos Reis. Porto Alegre, RS, Brasil.

${ }^{4}$ Enfermeira. Doutora em Enfermagem. Enfermeira do Hospital Universitário de Santa Maria. Santa Maria, RS, Brasil.

${ }^{5}$ Enfermeira. Doutora em Enfermagem. Docente do curso de graduação e da PósGraduação em Enfermagem da UFSM. Santa Maria, RS, Brasil. 


\section{Introdução}

A gestação pode ser caracterizada por um período repleto de mudanças físicas e emocionais, que podem ser vivenciadas de forma distinta por cada mulher. No entanto, requer cuidados especiais mediante às ações de acompanhamento pré-natal, a qual tem como objetivo acolher e acompanhar a mulher durante essa fase ${ }^{1}$.

A participação do pai, ao longo do período gravídico, pode ser decisiva na interação pai-filho, após o nascimento. Ao ser inserido nas ações de cuidado que envolvem o período gestacional, o companheiro pode construir vínculos de afeto e desenvolver a paternidade antes da chegada do novo ser. A mãe vivencia a maternidade precocemente, a partir das inúmeras transformações biológicas e psicológicas, que possibilitam a conexão entre a díade mãe-bebê, o que permite que o relacionamento destes seja construído ao longo desse período².

Considera-se, ainda, que a gestação é uma experiência desafiadora e repleta de mudanças, na qual a mulher e sua família precisam passar de forma saudável, encontrando apoio no serviço de saúde. Logo, por meio da assistência pré-natal, pode-se avaliar e monitorar todo o processo gravídico, detectar problemas precocemente, promover medidas educativas à mulher, companheiro e familiares, garantindo a atenção do bebê em desenvolvimento 3 .

Ao encontro disso, a família tem um importante papel no processo gravídico, principalmente porque as mulheres amparam-se em seus companheiros e mães, recebem aconselhamentos e apoio para a tomada de decisões durante a gravidez. A inclusão da família, nesse período de mudanças, também é essencial para que a gestante possa adquirir mais segurança e conhecimentos para praticar 0 autocuidado e 0 cuidado ao recém-nascido 4 .

Nesta esteira de pensamento, com o objetivo de construir mudanças no cenário das práticas de cuidado na atenção pré-natal, em 2000, foi criado pelo Ministério da Saúde o Programa de Humanização do Pré-natal e Nascimento (PHPN) ${ }^{5}$, o qual definiu elementos-chave da assistência à gestação e ao parto, em torno dos quais deveriam ser concentrados esforços a fim de reduzir as altas taxas de mortalidade materna. Consoante ao PHPN, a humanização do cuidado requer a adoção de valores de autonomia e protagonismo dos sujeitos, corresponsabilidade entre eles, solidariedade dos vínculos estabelecidos, direitos dos usuários e participação coletiva na gestão e serviços de saúde . $^{6}$.

Pode-se dizer, ainda, que humanizar a assistência implica em mudanças na atitude, na filosofia de vida e na percepção de si e do outro como ser humano. No processo de humanização, a sensibilidade, informação, comunicação e a responsabilidade precisam ser compartilhadas entre a mulher, os familiares e os profissionais de saúde ${ }^{6}$.

Pondera-se que a inclusão paterna no cuidado pré-natal se coaduna com as mudanças propostas no movimento em prol da humanização da assistência. Para tanto, são necessárias pesquisas que apontem características e necessidades das gestantes em relação ao atendimento pré-natal, a fim de contribuir positivamente para a sua melhoria ${ }^{7}$. Outrossim, a Organização Mundial de Saúde ${ }^{8}$ reforça a importância do desenvolvimento de pesquisas em saúde reprodutiva relativas à sexualidade, contracepção e à concepção, incluindo a gravidez, o parto e o puerpério, propondo que os valores, crenças, condição socioeconômica, entre outros, sejam considerados como eventos importantes. Assim, justifica-se esse estudo, o qual tem como objetivo compreender como as mulheres percebem a participação do homem no processo gravídico. A questão que guiou esta pesquisa foi: Como gestantes, assistidas no pré-natal de uma Unidade de Saúde de um município do interior do Rio Grande do Sul, percebem a participação de seus companheiros no processo gravídico?

\section{Metodologia}

Trata-se de uma pesquisa de campo do tipo descritiva com abordagem qualitativa, realizada em uma Estratégia de Saúde da Família (ESF), em um município do interior do Rio Grande do Sul, Brasil. Os critérios de inclusão envolveram gestantes que realizaram acompanhamento pré-natal na ESF e que estivessem convivendo com seus companheiros. Já os critérios de exclusão foram mulheres que não conseguiram compreender os questionamentos realizados pela pesquisadora.

Fizeram parte da pesquisa treze gestantes, convidadas intencionalmente no momento da consulta de pré-natal. Como técnica de coleta de dados, utilizou-se a entrevista semiestruturada, a qual permite ao entrevistado a possibilidade de discorrer sobre o tema proposto sem se prender à indagação formulada e sem respostas ou condições prefixadas pela pesquisadora ${ }^{9}$. Após o aceite da participação no estudo, a entrevista ocorria no mesmo dia ou em outra data agendada conforme a disponibilidade de cada gestante. 
As entrevistas foram realizadas na ESF, em uma sala específica, previamente combinada com a equipe. Após a gravação dos dados, eles foram transcritos para análise e interpretação das pesquisadoras. Para análise de dados, adotou-se a análise de conteúdo temática da proposta operativa9.

Toda a pesquisa foi amparada pela condução ética, sendo assegurado e valorizado os aspectos éticos e legais previstos na Resolução n. 196/96 do Conselho Nacional de Saúde, vigente na época em que ocorreu a pesquisa ${ }^{10}$. 0 projeto de pesquisa foi aprovado pelo Comitê de Ética em Pesquisa, sob número do processo 14351413.0.0000.5346.

Previamente à coleta de dados, foi disponibilizado às entrevistadas o Termo de Consentimento Livre e Esclarecido. As participantes foram informadas sobre o objetivo, riscos e benefícios da pesquisa.

\section{Resultados e Discussão}

Quanto à caracterização das participantes, a faixa etária variou entre 14 e 37 anos. Com relação ao grau de instrução, três tinham ensino médio completo, sete possuíam ensino médio incompleto, uma com ensino fundamental completo e duas tinham ensino fundamental incompleto. Cinco eram "do lar", uma estudante, uma atendente, uma balconista, uma caixa de mercado, uma sócia de um restaurante, duas diaristas e uma operadora de caixa.

Quanto ao número de gestações, seis estavam na sua primeira gestação, cinco na segunda, uma na terceira e uma na quarta gestação. Apenas uma delas vivenciou abortamento em alguma das gestações. À época da coleta de dados, a idade gestacional compreendeu entre treze e trinta e oito semanas de gestação aproximadamente.

Embora todas as gestantes estivessem morando junto com os seus respectivos companheiros, oito delas não tinham a união matrimonial e cinco eram oficialmente casadas. A faixa etária dos companheiros das gestantes entrevistadas variou entre 16 e 48 anos. Com relação ao grau de instrução, onze tinham o ensino médio incompleto, um possuía o ensino fundamental completo e um tinha ensino fundamental incompleto. Um era soldado da base aérea, um metalúrgico, um auxiliar de pedreiro, um soldador, um eletricista automotivo, um marmorista, um serviços gerais, um azulejista, um guarda noturno, um lixador de móveis, um estudante e dois pedreiros.

Frente à análise dos dados, emergiu o núcleo de sentido intitulado "Diferentes olhares sobre a participação do companheiro na gestação". Este núcleo diz respeito à percepção das participantes em relação à participação de seus companheiros na gestação. Ao longo das entrevistas, foi possível perceber que a maioria das gestantes se mostrou satisfeita com o apoio fornecido pelo companheiro.

Ele participa junto comigo em um monte de coisas [...] ah, ele vai junto nas consultas me levar, fica toda hora se preocupando, perguntando como é que eu estou sentindo, fica esperando ver se o nenê se mexer. (G3)

Eu nem sei o que eu ia fazer sem ele, porque para tudo ele tá sempre aqui, eu sei que posso contar com ele. É muito bom mesmo, muito bom. (G5)

Se ele vem junto ele aprende tudo que as gurias me dizem na consulta, fica mais fácil porque eu tenho medo de ele não saber as coisas para me ajudar na hora que depois o nenê nascer e tudo mais. (G6)

$\mathrm{Na}$ ótica das gestantes, o companheiro apresenta participação ativa no processo gestacional. Elas relatam a importância do apoio deste nesse período diferenciado e singular. A colaboração, as expectativas, a empatia e a compreensão permeiam as ideias das entrevistadas. Ao contarem com a participação do companheiro, elas demonstram maior tranquilidade e segurança, pois conseguem compartilhar as informações referentes ao pré-natal, a rotina nas consultas e são incentivadas na continuidade do acompanhamento.

Visualiza-se a importância da participação do companheiro, compartilhando todas as experiências vivenciadas junto com a gestante. É imprescindível o apoio do companheiro, tanto no acompanhamento da gestação, quanto na transmissão de sentimentos de segurança e afeto à mulher. Observa-se que a gestante que é apoiada pelo parceiro, torna-se mais confiante. Ao mesmo, o casal desenvolve atitudes de apoio e cuidados mútuos ${ }^{11}$. Conforme estudo ${ }^{11}, 0$ relacionamento afetuoso do bebê com a mãe ou com o pai é fundamental também para a promoção de satisfação no contexto familiar. Sendo assim, pai-mãe-feto precisam se sentir profundamente identificados um com o outro. 
Reforça-se, ainda, que o compartilhamento de responsabilidades permite que o casal não se sinta sobrecarregado em seus papeis e funções e, dessa forma, apresentem maior disposição para atender às necessidades de ambos e do bebê em desenvolvimento. Nesta lógica, o companheiro pode auxiliar diretamente nos cuidados à gestante e no contato com o bebê, o que contribui na preparação para a chegada deste novo integrante do grupo familiar.

Em outro estudo ${ }^{13}$, semelhante aos achados dessa pesquisa, muitas grávidas mencionam seus familiares e/ou companheiros como referências importantes na gestação, por contribuírem tanto com informações sobre o processo gestacional, como pelo apoio emocional que lhes propiciavam. $O$ autor ${ }^{13}$ relata, ainda, que nos últimos anos, observa-se um aumento expressivo de companheiros envolvidos no processo gestacional. Eles se sentem motivados em fornecer apoio material e emocional às gestantes e envolver-se com o bebê.

Esta atitude demonstra uma modificação quanto à participação do companheiro no processo de paternidade ainda no período gestacional. Logo, infere-se que o companheiro tem buscado maior aproximação e envolvimento com a vivência deste processo e que a responsabilidade sobre a gestação e os cuidados com o bebê não tem se restringido a um papel estritamente feminino ${ }^{13}$.

Por outro lado, uma participante relatou insatisfação com relação à participação do companheiro no período gravídico. Esta falta de envolvimento, se não modificada após o nascimento, pode influenciar diretamente na relação entre pai, mãe e bebê.

Ah não, ele não participa não, em quase nada. Ele é um ótimo pai mesmo, mas só depois que nasce. Eu imagino que eu ia ser bem mais feliz durante a gravidez se ele tivesse mais junto, porque a gente se sente muito sozinha quando está grávida. Então, quando está com uma pessoa assim que nem ele, que não dá muita atenção, aí eu acho que é pior ainda. (G4)

Percebe-se a insatisfação da gestante devido à falta de atenção, o distanciamento e a insegurança proporcionada pela ausência do companheiro na vivência desse processo. Essa relação pode impactar diretamente na saúde da gestante e do feto, geralmente de maneira negativa, conforme comentado em estudo $0^{11}$ sobre a ausência do companheiro nos cuidados gestacionais e na consulta pré-natal. Quando o companheiro não participa do processo gestacional, os desconfortos advindos da gestação podem ser intensificados, assim como o próprio bem-estar das gestantes e a relação conjugal.

Nesse sentido, a gestação pode ser permeada por sensações opostas àquelas esperadas. Portanto, além de todas as mudanças físicas, psicológicas e culturais inerentes ao período, a mulher ainda precisa enfrentar a ausência do companheiro. Assim, é preciso destacar algumas barreiras que obstacularizam o envolvimento do companheiro nos cuidados gestacionais, como a imaturidade, o despreparo para tornar-se pai e o ciúme da relação mãe-feto ${ }^{13}$.

Contudo, também é possível encontrar companheiros que participam em demasia. Nestes casos, o envolvimento da mulher é colocado em segundo plano e o casal não consegue vivenciar o processo em conjunto.

Eu vejo que ele está bem faceiro. Ele se preocupa com tudo, cada vez que ele vai até o centro ele aparece com uma coisa diferente para o nenê. Ele comprou o berço do nenê por conta, comprou roupinha por conta, comprou a cômoda do nenê, e eu apenas comprei umas roupinhas poucas para ele e não deu para pegar mais nada, ele tinha visto tudo, eu me senti mal, parecia que só ele estava interessado sabe. (G1)

A fala revela como a gestante se sente perdendo espaço para vivenciar o preparo para receber o bebê, ao perceber que o companheiro está agindo individualmente, em algumas atividades em que ela gostaria de estar inserida. Entende-se que a atitude isolada dele, sem inclui-la, confere um caráter negativo à experiência gestacional. Diante da chegada do novo membro da família, a gestante elaborou expectativas e a dificuldade do companheiro em compartilhar os preparativos com ela, favoreceu a sensação de isolamento e exclusão das decisões e ações.

Percebeu-se, com isso, a importância da participação conjunta do casal no período gestacional. A participação isolada de um dos membros da família pode influenciar negativamente a vivência da gestação, talvez pela sensação de isolamento $e$ exclusão que se impõe; ou pela insegurança que se cria, quando é menor a participação masculina na gestação. Logo, reforçase a importância da participação conjunta do casal, fundamental para a família se estabelecer como um grupo em formação. 


\section{Considerações Finais}

A participação dos companheiros no período gestacional revelou-se sobre diferentes perspectivas. Algumas gestantes se sentem satisfeitas com o cuidado prestado pelo companheiro, outras estão descontentes com o envolvimento deles na gestação e no pré-natal. A maioria manifestou o desejo de poder contar com o apoio do companheiro nessa fase e o medo e insegurança que demonstraram ao considerar sobre a gestação sem o apoio deles. Nessa direção, entende-se que esses achados precisam ser destacados nos encontros pré-natais, sempre que possível, a fim de propiciar condições favoráveis para a construção dos papeis referente à maternidade e à paternidade, além de fortalecer a relação do casal neste processo.

Assim, infere-se que a vivência da gestação pode ser mais positiva quando as mudanças inerentes ao processo gestacional são experenciadas com o apoio do companheiro. Sugere-se a importância de novos estudos que envolvam o homem/companheiro e o período gravídico-puerperal, visto a escassa quantidade de literatura sobre o tema na área da enfermagem e a necessidade de modificar este contexto, colocando o homem "junto", "ao lado" e não como um mero expectador deste processo.

\section{Referências}

1. Melo MCP, Coelho NHN, Creôncio SCE. Atuação da enfermeira no pré-natal: uma revisão a partir da sistematização, da humanização e da educação em saúde. Enciclopédia biosfera [Internet]. 2010 [acesso em: 28 jun 2015];5(10):1-18. Disponivel em: http://www.conhecer.org.br/enciclop/2010b/atuacao.pdf

2. Benazzi AST, Lima ABS, Souza AP. Pré-natal masculino: um novo olhar sobre a presença do homem. Rev pol públ [Internet]. 2012 [acesso em: 15 nov 2014];15(2):327-33. Disponível em: http://www.periodicoseletronicos.ufma.br/index. php/rppublica/article/view/849

3. Coutinho T, Monteiro MFG, Sayd JD, Teixeira MTB, Coutinho CM, Coutinho LM. Monitoramento do processo de assistência pré-natal entre as usuárias do Sistema Único de Saúde em município do Sudeste brasileiro. Rev Bras ginecol obstet. [Internet] 2010 [acesso em: 12 jan 2013];32(11):563-9. Disponível em: http://www.scielo.br/scielo.php?pid=S010072032010001100008\&script=sci_arttext

4. Silva CO, Santos JLG, Pestana AL, Bernardi MC, Erdmann AL. Significados e expectativas de gestantes em relação ao pré-natal na atenção básica: revisão integrativa. Saúde \& Transf social [Internet] 2013 [acesso em: 10 nov 2014];3(4):98104. Disponível em: http://incubadora.periodicos.ufsc.br/index.php/saudeetransformacao/article/view/1958

5. Ministério da Saúde. Secretaria de Políticas de Saúde, Área Técnica da Saúde da Mulher. Programa de Humanização no Pré-natal e nascimento: informações para gestores e técnicos; Ministério da Saúde; 2000.

6. Ministério da Saúde. Cadernos HumanizaSUS: Atenção Básica; Ministério da Saúde; 2010.

7. Costa CSC, Vila VSC, Rodrigues FM, Martins CA, Pinho LMO. Características do atendimento pré-natal na Rede Básica de Saúde. Rev Eletr Enf [Internet] 2013 [acesso em: 15 jan 2015];15(2):516-22. Disponível em: https://www.fen. ufg.br/fen_revista/v15/n2/pdf/v15n2a26.pdf

8. Osis MJD. Abordagens qualitativas em saúde reprodutiva. In: Barros NF, Cecatti JG, Turato ER, organizadores. Pesquisa qualitativa em saúde: múltiplos olhares. Campinas: Komedi; 2005. p.121-33.

9. Minayo MCS. O desafio do conhecimento: pesquisa qualitativa em saúde. 12. ed. São Paulo: Hucitec; 2013.

10. Ministério da Saúde. Conselho Nacional de Saúde. Diretrizes e normas regulamentadoras de pesquisa envolvendo seres humanos. Resolução n. 196, Ministério da Saúde; 1996.

11. Silva FCB, Brito RS. Ausência do homem nas consultas de pré-natal: o que significa para a gestante? Curitiba: Appris; 2011.

12. Barbosa FA, Machado LFV, Souza LV, Scorsolini-Comin F. Significados do cuidado materno em mães de crianças pequenas. Barbarói. [Internet] 2010 [acesso em: 28 nov 2015];(33):28-49. Disponível em: http://pepsic.bvsalud.org/scielo. php?pid=S0104-65782010000200003\&script=sci_arttext

13. Piccinini CA, Carvalho FT, Ourique LR, Lopes RS. Percepções e Sentimentos de Gestantes sobre o Pré-natal. Psicologia: Teoria e Pesquisa [Internet] 2012 [acesso em: 13 nov 2015];28(1):27-33. Disponível em: http:/www.scielo.br/pdf/ptp/v28n1/04.pdf 


\section{Lisie Alende Prates}

Endereço para correspondência - Universidade Federal de Santa Maria Departamento de Enfermagem - Programa de Pós-Graduação em Enfermagem,

Prédio 26, Av. Roraima, n 1000, CEP: 97105- 900, Santa Maria, RS, Brasil.

E-mail: lisiealende@hotmail.com

Lattes: http://lattes.cnpq.br/5830359833199428

Naiashy Vanuzzi Martello - nayvanuzzi@gmail.com

Laís Antunes Wilhelm - laiswilhelm@gmail.com

Luiza Cremonese - lu_cremonese@hotmail.com

Camila Neumaier Alves - camilaenfer@gmail.com

Lúcia Beatriz Ressel - Ibressel208@yahoo.com.br

Enviado em 12 de setembro de 2015. Aceito em 05 de junho de 2017. 